\title{
Craniomicromelic Syndrome: A Newly Recognized Lethal Condition With Craniosynostosis, Distinct Facial Anomalies, Short Limbs, and Intrauterine Growth Retardation
}

\author{
Mason Barr, Jr., Kathleen P. Heidelberger, and Christine H. Comstock \\ Departments of Pediatrics (M.B.), Pathology (M.B., K.P.H.), and Obstetrics and Gynecology (M.B.), University of \\ Michigan, Ann Arbor, and Department of Obstetrics (C.H.C.), William Beaumont Hospital, Royal Oak, Michigan
}

\begin{abstract}
We report on two sisters with an unusual form of craniosynostosis, protruding nasal spine, micrognathia, short limbs, lung hypoplasia, absent or hypoplastic gallbladder, short intestine with ileal distention, hypoplastic uterus, and intrauterine growth retardation. This combination of defects appears to be a newly recognized and probably autosomal recessive disorder.

(c) 1995 Wiley-Liss, Inc.
\end{abstract}

KEY WORDS: craniosynostosis, micromelia, autosomal recessive

\section{INTRODUCTION}

Syndromes with craniosynostosis have been reviewed extensively elsewhere [Cohen, 1986, 1988] and, to date, it is estimated that there are about 90 syndromes with craniosynostosis as one manifestation [Cohen, 1993]. Here, we report on a newly recognized syndrome of craniosynostosis, distinct facial malformations, short limbs, intrauterine growth retardation, and other anomalies. The condition is clearly different from previously reported craniosynostosis syndromes.

\section{CLINICAL REPORTS}

The first girl was born at 40 weeks of gestation to healthy, non-consanguineous, 28-year-old parents, with no teratogenic exposures and no family history of birth defects. The pregnancy had been remarkable for small fundal height for dates. Fetal ultrasonography showed a growth restricted fetus with short but straight limbs, an abnormal skull, a small thorax, "poor

Received for publication November 8, 1994; revision received March 20, 1995.

Address reprint requests to Dr. Mason Barr, Jr., Pediatric Genetics-Teratology, D1109 MPB 0718, University of Michigan, Ann Arbor, MI 48109. ossification," ventriculomegaly, and hydronephrosis. These findings were confirmed by serial exams. Her birth weight was $1.46 \mathrm{~kg}$ and Apgar scores were 2 and 2 at 1 and 5 minutes; she died 30 minutes after delivery. Her lymphocyte metaphase karyotype was $46, \mathrm{XX}$, normal.

The mother's second pregnancy was examined by ultrasonography at 14 weeks, at which time the fetal size was deemed appropriate for dates. At 17.5 weeks, all fetal measurements were consistent with an age of 15 weeks. At 22 weeks, all measurements except the cerebellar diameter were small for dates (biparietal diameter $4 \mathrm{~cm}$, femur length $2.1 \mathrm{~cm}$, head circumference $16.2 \mathrm{~cm}$, abdominal circumference $10.3 \mathrm{~cm}$, fibula $1.74 \mathrm{~cm}$, humerus $2.10 \mathrm{~cm}$, and radius $1.68 \mathrm{~cm}$ ). The ratio of the head to abdominal circumference was 5 standard deviations below normal, reflecting the unusually small abdomen. The head shape was normal in the axial plane, and the outer and inner orbital diameters were proportional to head size. There was no hydrocephaly. The lips were intact, but the chin appeared to be small. The chest was bell shaped but its circumference, although small, was proportional to the rest of the body. The gallbladder could not be seen. The bowel pattern was normal for gestational age. The limbs were slightly shorter than expected for the degree of growth restriction. Bone density and shape were normal. The distal arms were shorter than expected for humeral length, but the legs were proportionate to the femora. The feet appeared to be normally related to the legs. The toes could not be visualized, but the fingers appeared to be normal. The pregnancy was terminated electively at 24.1 weeks. Birth weight was $190 \mathrm{~g}$.

Both infants had relative macrocephaly and turricephaly (Figs. 1, 2). Both had short palpebral fissures, but while the eyes of the older infant were small and "dysplastic" the eyes of the younger one were apparently unremarkable. The nose of each was pinched at the tip with anteverted nares, and each had a distinct and marked protrusion of the nasal spine midway along the bridge of the nose (Figs. 3, 4). Both had marked micrognathia and microstomia, and the 


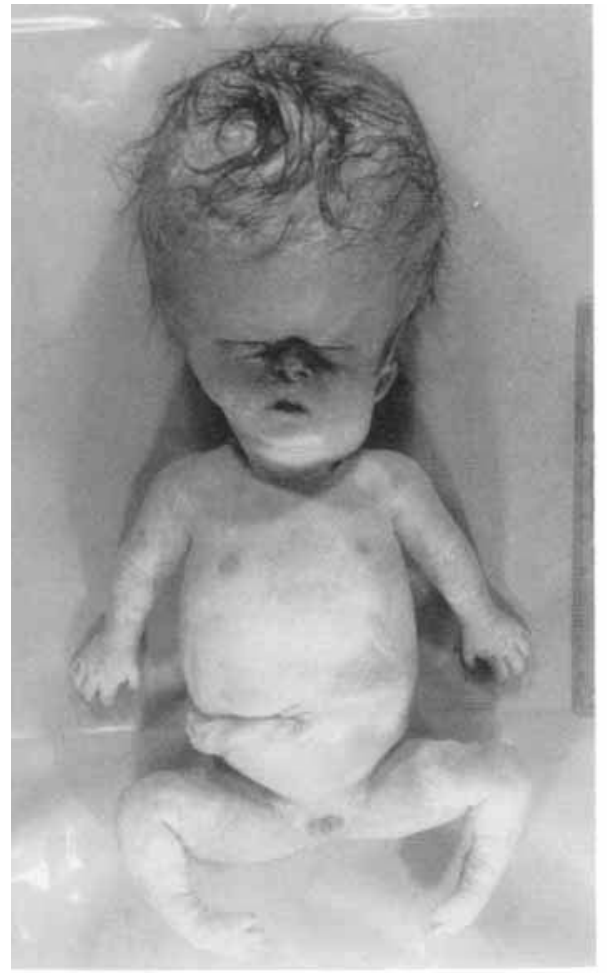

Fig. 1. AP Case 1. Note the disproportion between head and body the short limbs, and the facial abnormality.

younger one had a U-shaped cleft palate. Their ears were low-set and posteriorly angulated, and those of the older infant were short.

In the older infant, the posterior contour of the skull was marked by a low occipital protrusion that was incompletely invested with bone but completely invested with a dense fibrous tissue (like that associated with fontanels); this protrusion contained herniated cerebellum. The superior margin of this protrusion was demarcated by a thick ridge of bone, and this was the site of the tentorial attachment. Rostral to this the occipital bone swept posteriorly, at a $55^{\circ}$ angle, forming a second bulge. The lambdoid sutures were patent but with very ragged margins of both the occipital and parietal bones. The apex of the occipital bone was marked by a short midline notch (extension of the sagittal suture). The squamosal sutures were patent to the greater wing of the sphenoid, but again the margins were ragged ("coast of Norway") and lacunar. The parietals were of very irregular thickness (dendritic ridging and lacunae). The sagittal suture was wide $(5 \mathrm{~cm})$ and virtually indistinct from the posterior and anterior fontanels. At the posterior margins of the parietals were islands $(5 \times 2 \mathrm{~cm})$ of bone bilaterally.

The coronal sutures were not evident; internally there was a somewhat thickened ridge where the coronal suture would ordinarily be, but externally there was no clue to the presence of a suture. The frontal bones were virtually nonexistent above the supraorbital rims. Instead there was a huge metopic "fontanel"

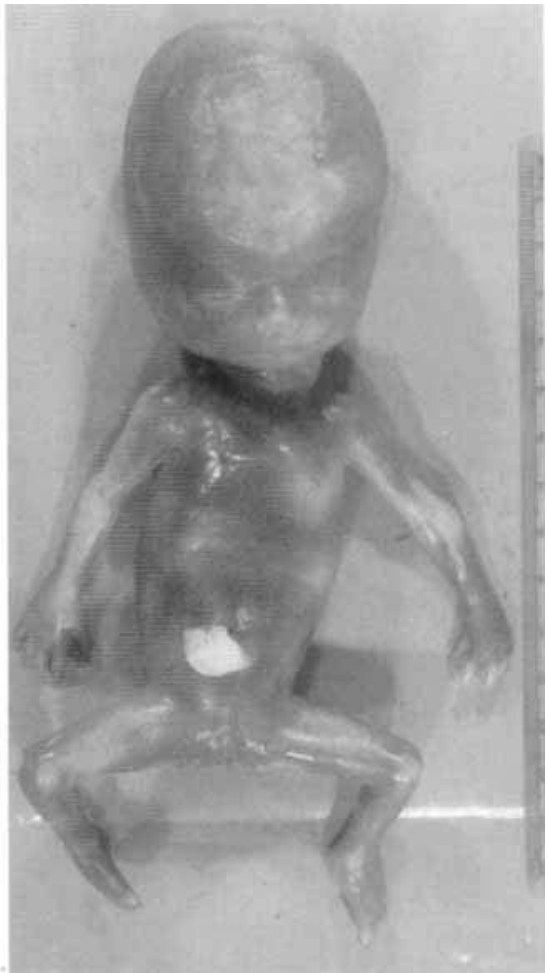

Fig. 2. AP Case 2. Note the disproportion between head and body, the short limbs, and the facial appearance.

continuous with the anterior fontanel. The orbital roofs were distinctly lacunar. The skull base, from the cribriform plate to the foramen magnum, was in a single plane positioned at about $30^{\circ}$ to the line of the occipital bone, averaging out the two occipital bulges to a single line. The posterior wall of the sella turcica was canted forward and the middle cranial fossae were rather deep. There was occipito-atlantic instability with about

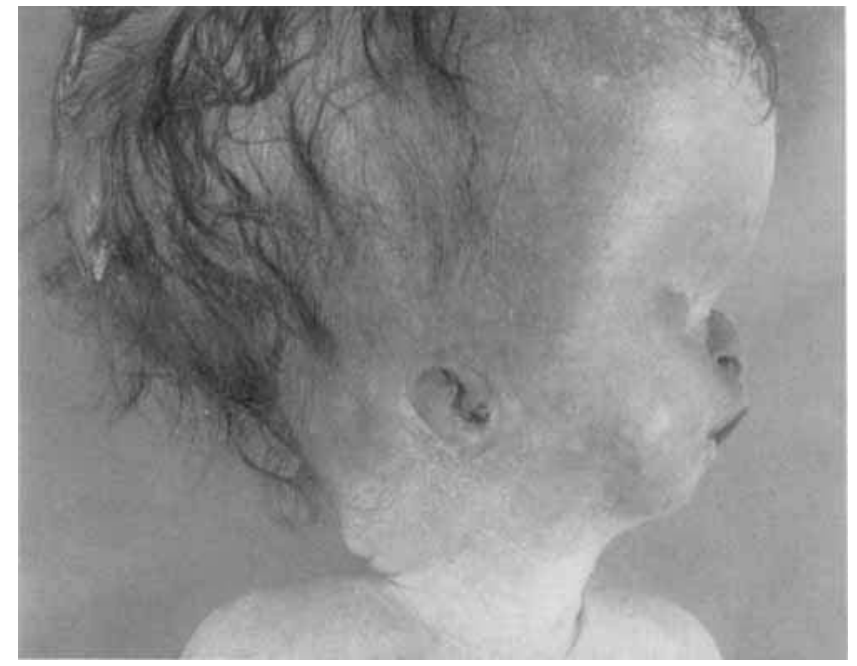

Fig. 3. Face profile Case 1. Note the short nose and protruding nasal spine. 


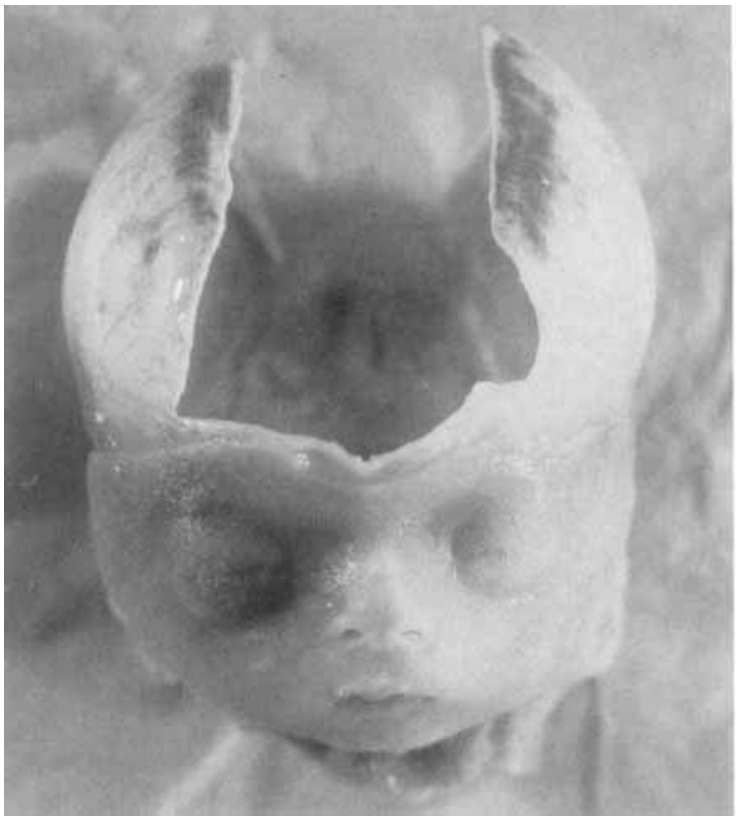

Fig. 4. Face-skull Case 2. Interosseous soft tissue has been removed to demonstrate the deficient frontal bones and large fontanels.

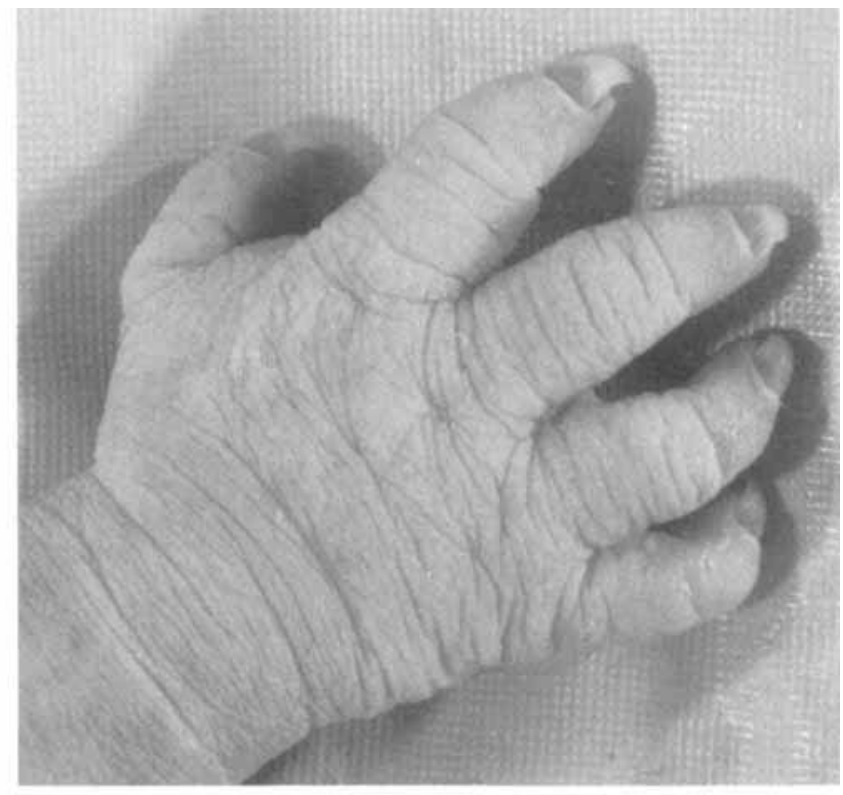

Fig. 5. Hand-nails Case 1. Note the short, tapered fingers with talon-like nails.

lung, was absent from the distal airways. The hearts showed ventricular myocardial hyperplasia, and the right coronary artery ostium was eccentric in the older infant. Each had a hypoplastic/absent gallbladder and short intestines (midgut and colon). Both had marked meconium distention of the mid-ileum (Fig. 6), but the gut in this region and distally had normal ganglion cells.

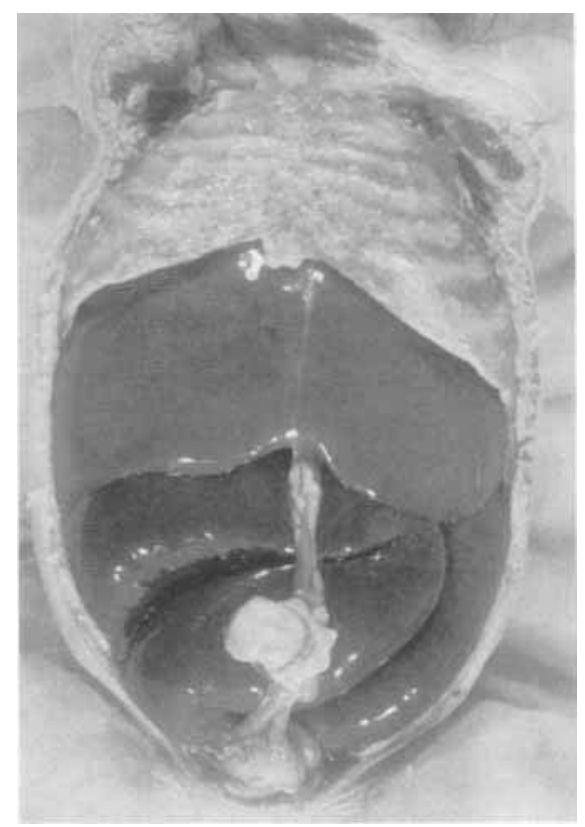

Fig. 6. Thorax-abdomen Case 1. Note the marked intestinal (ileum) distention. dilated to the periphery of the lungs. Cartilage, which appeared to be normal in the trachea and hilum of the 
Both had a hypoplastic uterus and short fallopian tubes; the labia majora of the older infant were hypoplastic. The older one also had marked hydronephrosis but a locus of ureteral obstruction could not be identified.

Roentgenograms of both infants showed short but otherwise normally configured long bones and no other abnormalities beyond those of the skull (Figs. 7, 8). Microscopically the bone and cartilage were unremarkable.

\section{DISCUSSION}

These sibs had coronal craniosynostosis with large fontanels, a distinct protrusion of the nasal spine, symmetrically short limbs with normal bone morphology, and intrauterine growth retardation. We propose the name craniomicromelic syndrome to identify this newly recognized condition. Two affected sibs, with normal chromosomes in one, from unaffected parents suggests autosomal recessive inheritance.

Despite the large number of craniosynostosis syndromes, the combination with short limbs and lethality limits the differential diagnosis. Both thanatophoric dysplasia (TD), type 2 [Langer et al., 1987], and IvesHouston syndrome [Ives and Houston, 1980] are lethal conditions with craniosynostosis (cloverleaf skull in the former) and short limbs. However, both have more dramatically short limbs with distinctive radiographic appearance than in craniomicromelic syndrome. In TD, type 2, the limb bones are short and thick; other radi-

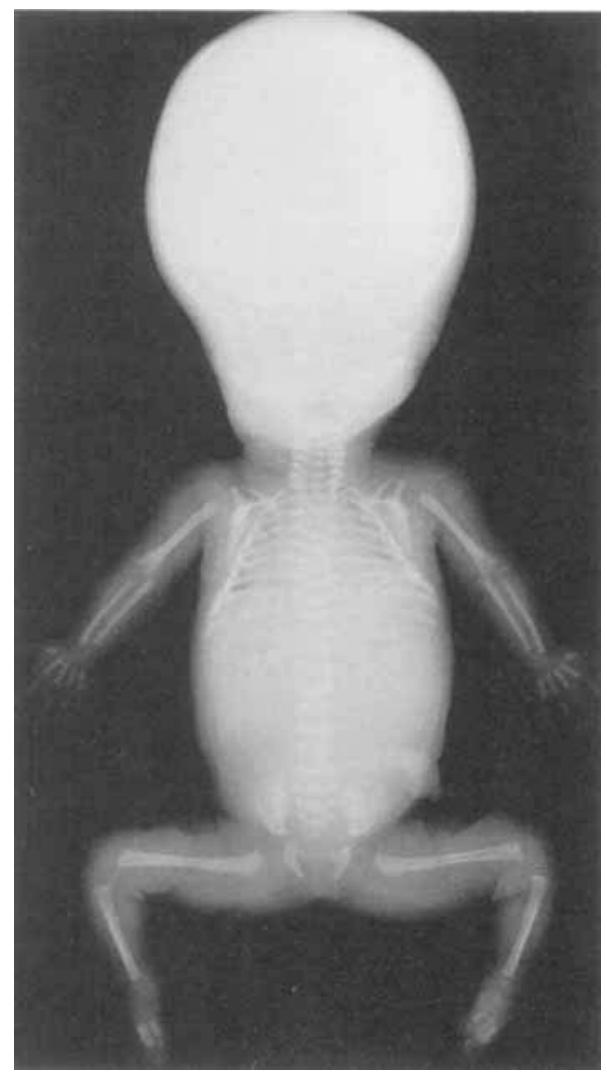

Fig. 7. AP X-ray Case 1. Other than in the cranium there are no skeletal anomalies.

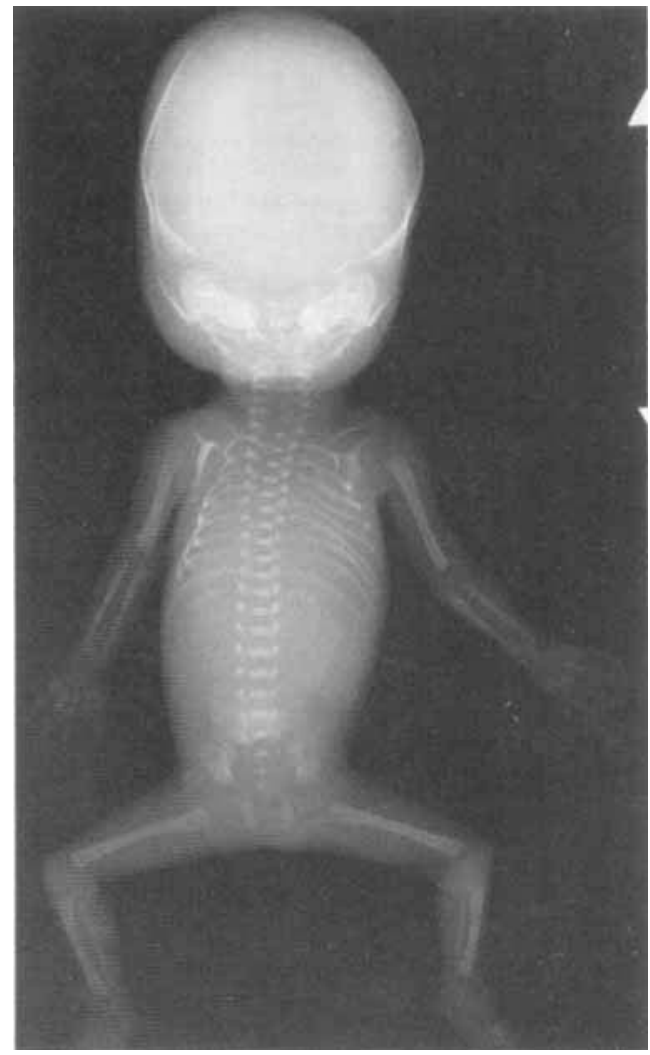

Fig. 8. AP X-ray Case 2, Other than in the cranium there are no skeletal anomalies.

ographic findings include narrow thorax, short flared ribs, platyspondyly, narrow sacrosciatic notches, and horizontal acetabular roofs with spurring. In the autosomal recessively inherited Ives-Houston syndrome the elbows are fused, the forearms dramatically short, and the fingers varying from two-to-four in number.

The fetal aminopterin syndrome has several features in common with craniomicromelia, notably hypoplasia of the frontal bones, wide fontanels, craniosynostosis, micrognathia, cleft palate, low-set ears, and short limbs [Jones, 1988]. However, the facial features in craniomicromelia are quite different, and the mother of these sibs was not exposed to aminopterin or other folate antagonist. Campomelic syndrome of the craniosynostotic type, Carpenter syndrome [Cohen, 1986], and cranioectodermal dysplasia [Levin et al., 1977] are easily distinguishable from craniomicromelic syndrome.

\section{ACKNOWLEDGMENTS}

We are grateful to Michael Cohen for helpful comments and suggesting a name for this disorder. We are especially appreciative of the parents' generosity in permitting this study of their babies.

\section{REFERENCES}

Cohen MM Jr (1986): "Craniosynostosis: Diagnosis, Evaluation, and Management.” New York: Raven Press. 
Cohen MM Jr (1988): Craniosynostosis update: 1986-1987. Am J Med Genet Suppl 4:99-148.

Cohen MM Jr (1993): Sutural biology and the correlates of craniosynostosis. Am J Med Genet 47:581-616.

Ives EJ, Houston CS (1980): Autosomal recessive microcephaly and micromelia in Cree Indians. Am J. Med Genet 7:351-360.

Jones KL (1988): "Smith's Recognizable Patterns of Malformation," 4th Edition. Philadelphia: WB Saunders, pp 506-507.
Langer LO Jr, Yang SS, Gilbert EF, Hall JG, Sommer AM, Kottamasu S, Golabi M, Heidelberger K, Krassikoff N (1987): Thanatophoric dysplasia and cloverleaf skull: A report of nine new cases and a review of the literature. Am J Med Genet Suppl 3:167-179.

Levin LS, Perrin JCS, Ose L, Dorst JP, Miller JD, McKusick VA (1977): A heritable syndrome of craniosynostosis, short thin hair, dental abnormalities and short limbs: Cranioectodermal dysplasia. J Pediatr 90:55-61. 